\title{
STEREOLOGICAL EVALUATION OF BRAIN MAGNETIC RESONANCE IMAGES OF SCHIZOPHRENIC PATIENTS
}

\author{
AMANI ELFAKI ${ }^{\bowtie, 1}$, ABDELRAZAG ELFAKI $^{2}$, TAHIR OSMAN $^{3}$, BUNYAMIN SAHIN $^{1}$, ABDELGANI $^{3}$ \\ ElSHEIKH $^{3}$, AMIRA MOHAMED $^{4}$, AnAS HAMDOUN $^{5}$, ABDELRAHMAN MOHAMMED $^{3}$ \\ ${ }^{1}$ Department of Anatomy, Medical School, Ondokuz Mayis University, Samsun 55139, Turkey; ${ }^{2}$ Department of \\ Psychiatry, Ahfad University for Women, Omdurman, Sudan; ${ }^{3}$ Departments of Anatomy, Psychiatry and Radi- \\ ology, Faculty of Medicine, Ribat University, Burri 55 Khartoum, Sudan; ${ }^{4}$ Tigani Almahi Psychiatric hospital, \\ Khartoum, Sudan; ${ }^{5}$ Gazira University, Faculty of Medicine, Department of Radiology, Wad Medani, Sudan \\ e-mail: amani.elfaki@omu.edu.tr, amanielfaki@gmail.com, bsahinomu@gmail.com, \\ Abdelrazagelfaki@gmail.com, ali.taher56@yahoo.com, abdelghani55@hotmail.com, abdalrahman- \\ noor@hotmail.com,Hamdoun11@hotmail.com, amiraharoun@hotmail.com \\ (Received March 7, 2013; revised July 11, 2013; accepted August 8, 2013)
}

\begin{abstract}
Advances in neuroimaging have enabled studies of specific neuroanatomical abnormalities with relevance to schizophrenia. This study quantified structural alterations on brain magnetic resonance (MR) images of patients with schizophrenia. MR brain imaging was done on 88 control and 57 schizophrenic subjects and Dicom images were analyzed with ImageJ software. The brain volume was estimated with the planimetric stereological technique. The volume fraction of brain structures was also estimated. The results showed that, the mean volume of right, left, and total hemispheres in controls were 551,550 , and $1101 \mathrm{~cm}^{3}$, respectively. The mean volumes of right, left, and total hemispheres in schizophrenics were 513, 512, and $1026 \mathrm{~cm}^{3}$, respectively. The schizophrenics' brains were smaller than the controls $(\mathrm{p}<0.05)$. The mean volume of total white matter of controls $\left(516 \mathrm{~cm}^{3}\right)$ was bigger than the schizophrenics' volume $\left(451 \mathrm{~cm}^{3}\right),(\mathrm{p}<0.05)$. The volume fraction of total white matter was also lower in schizophrenics $(p<0.05)$. Volume fraction of the lateral ventricles was higher in schizophrenics $(p<0.05)$. According to the findings, the volumes of schizophrenics' brain were smaller than the controls and the volume fractional changes in schizophrenics showed sex dependent differences. We conclude that stereological analysis of MR brain images is useful for quantifying schizophrenia related structural changes.
\end{abstract}

Keywords: brain, Cavalieri principle, magnetic resonance images, schizophrenia, stereology, volume, volume fraction

\section{INTRODUCTION}

Advances in neuroimaging have cleared the way for studies on specific neuroanatomical abnormalities with relevance to schizophrenia. Schizophrenia is a psychotic disorder with delusions, hallucinations, disorganized behavior and speech, and negative symptoms (Spitz and Sadock, 1973). Despite its unknown etiology, Bleuler, who first described the disease, in a lecture in Berlin on 24 April 1908, believed that a relationship between the structural brain abnormalities and the etiology of schizophrenia exists (Peralta and Cuesta, 2011).

With the first magnetic resonance imaging (MRI) study in schizophrenia by Smith et al. (1984), the researchers were offered a unique opportunity to examine special brain areas in live patients. Unlike computed tomography (CT) scan, MRI can discriminate the grey and white matter of brain with much better resolution, so that MRI has become the imaging modality of choice in evaluation of the brain changes during schizophrenia (Shenton et al., 2001).

When evaluating the volumes of different structures in the brain, it is necessary to determine the total cerebral volume to find out if the change in the volume of those structures is secondary to overall changes in the cerebral volume or has occurred independently. MRI studies have reported changes in the brain volume (Sanfilipo et al., 2000), and the volume of lateral ventricles (Rajarethinam et al., 2000). Moreover, some studies suggested that brain morphology could predict the course of the disease and the outcome for neuroleptic drugs used (Ebdrup et al., 2011).

The majority of structural brain imaging studies in schizophrenia, thus far, have been confined to adult 
subjects, only a few studies have explored whole-brain changes in early-onset schizophrenia on a morphometric basis (Sowell et al., 2000; Thompson et al., 2001; Vidal et al., 2006). Despite a prolific literature, the structural cerebral changes revealed in adult-onset schizophrenia have previously shown great inconsistencies, partly due to the heterogeneity of the methods applied and to methodological problems in working with this patient population, such as the appropriate interpretation of the enlargement of ventricles (Kubicki et al., 2005; Walterfang et al., 2006; Kubicki et al., 2007). In performing the work described here, advantage of recent advances in grey matter stereology and white matter integrity analyses was taken, as well as the lateral ventricular volume in appropriate statistical inferences.

Many biomedical studies have applied unbiased stereological methods in combination with non-invasive MRI (Gong et al., 1998). For example, the reliability of the Cavalieri estimator and point counting in combination with MRI to estimate the volume of biological structures based on systematic sampling has been investigated in several studies (Gundersen et al., 1999). However, the accuracy of these estimators has been evaluated by only a few researchers (Doherty et al., 2000; Garcia-Finana et al., 2003).

The aim of the present study was the stereological quantification of schizophrenia related brain changes on MRI in combination with stereology, to detect structural alterations of the cerebrum in schizophrenics. It also aims to present what Hippocrates already knew in the fourth century B.C. "almost everything that we think, do and feel derive from the brain. Mental illness arises from the brain when it is not healthy". The repeatability and reproducibility of procedure in this study was investigated to ensure consistency of the measurements.

\section{MATERIAL AND METHODS}

88 control subjects (51 male, 37 female) and 57 schizophrenic patients (30 male, 27 female) participated in the present study. The total number of volunteers was 145 . The details of the mean of ages and body mass index of the participants are describe in the table 1 . The study was approved by the Ethical Committee of the Gezira University/ Sudan. Patients or patient's relatives and controls consented to all procedures.

\section{CRITERIA OF SELECTION}

Adults Sudanese who are clinically diagnosed as schizophrenic patients. All schizophrenic patients met ICD/10 criteria and were receiving regular antipsychotic medication. The patients were selected from: Professor Abdelaal Alidresi Psychiatric hospital, Tigani Almahi Psychiatric hospital, and private psychiatric clinics in Sudan.

Controls were Sudanese volunteers with no history of psychiatric disorders and drug medication. Control subjects were matched with patients on the basis of gender and age.

Exclusion criteria for both patients and controls include a head trauma, drug abuse and central neurological disorders.

\section{MRI ACQUISITION}

Structural MRI was done to both patients and controls in the Department of Radiology in the National Ribat University. The MR scanner used was a SIEMENS 1.5 Tesla Magnetom Avanto Vision System. T1-weighted images were obtained using three-dimensional acquisition by Magnetization Prepared Rapid Acquisition (MP-RA); it produces good grey/white matter contrast in a very short acquisition time. Slice distance was $1.0 \mathrm{~mm}$, the field of view was $250 \mathrm{read}, 192 \mathrm{~mm}$ phase, $\mathrm{TR}=1657 \mathrm{~ms}, \mathrm{TE}=2.95$ ms, bandwidth $180 \mathrm{~Hz} /$ pixel, flip angle $15^{\circ}$, ECHO spacing $=7.5 \mathrm{~ms}$, phase resolution $=100 \%$, slice resolution $=50 \%$, and acquisition time $=5 \mathrm{~min}$ and $18 \mathrm{sec}$. The images were made in the coronal section.

This T1-weighted sequence is part of the standard clinical protocol for qualitative and quantitative analysis of the whole brain in patients with epilepsy.

\section{METHODS OF MEASUREMENTS}

Morphometric measurements were conducted blind to the clinical data using ImageJ software. The ImageJ is produced and distributed by the National Institute of Health (NIH). The software is in the public domain and was downloaded from the Internet (available at the site: http://rsb.info.nih.gov/ij/). It runs on any computer system. Measurements from images can be stored separately. The Dicom brain images were transferred to the ImageJ software and converted into a stack. Systematic random sampling was done since the number of slices in coronal plane was about 192 sections. The sampling fraction was $1 / 10$ and $1 / 5$ for the brain and ventricles, respectively. This means, for example taking the $5^{\text {th }}$ section as first, then going on to the sections 15, 25, 35 for the brain. Therefore, the section interval for the brain was $1 \mathrm{~cm}$ and for the ventricle $0.5 \mathrm{~cm}$. Finally 15 to 17 sections containing brain images and 14 to 20 sections containing ventricles were obtained. 
The midline of the brains and possible borders of the hemispheres were drawn on the images to delineate them from the surrounding tissues (Fig. 1A). The outer boundaries of the hemisphere were manually delineated (Fig. 1B). A threshold tool was used to delineate the boundaries of the white matter, and then the wand tool was used to delineate the boundaries of the hemispheres (Fig. 1C). This procedure was also done for the ventricles (Fig. 1D). The sectional cut surface of the structure of interest was measured by the software automatically. The volume of cerebral hemispheres, ventricles and white matter was estimated by the multiplication of the total sectional surface area with the section interval (i.e., $1 \mathrm{~cm}$ and $0.5 \mathrm{~cm}$ for the hemisphere and ventricle, respectively) as it shown in the formula

$$
\mathrm{V}=\sum \mathrm{a} \times \mathrm{t},
$$

where, $\mathrm{V}$ is the volume, $\sum \mathrm{a}$ is the total sectional area of the structure and $t$ is the space between the examined sections.

The total brain volume was estimated by summating the volumes of both hemispheres, and grey matter volume was obtained by subtracting the volume of white matter and ventricles from the total hemispheric volume.

For the measurements of the volume fraction the following formula was used:

Volume fraction $=\frac{\text { Volume of } X \text { phase in } Y \text { reference space }}{\text { Volume of } Y \text { reference space }}$,

where the $\mathrm{V}_{\mathrm{V}}(\mathrm{X}, \mathrm{Y})$ indicates volume fraction of $\mathrm{X}$ phase within the $Y$ reference volume. Using this approach, $\mathrm{V}_{\mathrm{V}}$ (hippocampus, brain), $\mathrm{V}_{\mathrm{V}}$ (cortex, total brain volume) and $\mathrm{V}_{\mathrm{V}}$ (tumor, hemisphere) can be estimated. Volume fraction ranges from 0 to 1 and is often expressed as a percentage.
In the planimetry method, the coefficient of error (CE) of estimates was obtained using the following formula:

$$
C E=\left(\sum_{i=1}^{n} A_{i}\right)^{-1} \times\left[\frac{1}{240}\left(3 \sum_{i=1}^{n} A_{i}^{2}-4 \sum_{i=1}^{n-1} A_{i} A_{i+1}+\sum_{i=1}^{n-2} A_{i} A_{i+2}\right)\right]^{1 / 2} .
$$

Where, $\mathrm{i}=1,2, \ldots, \mathrm{m}$ is the number of sections. $\mathrm{A}$ is the measured area of the sections using planimetry and the others are constants. This formula allows the researcher to evaluate the area changes and the measured cut surface areas in the consecutive section series (Mazonakis et al., 2002).

The calculations and the $\mathrm{CE}$ values were done with Microsoft Excel. A spreadsheet was prepared and the surface area data were transferred from ImageJ to Excel where the calculations were done automatically.

Two weeks later the same procedure was applied and the same observer obtained the volume data. The details of the intra-rater variation are reported in the paper published by Elfaki et al. (2011).

Wilcoxon's signed-rank test was applied to compare the results of first and second sessions. Pearson correlation test was done to see the relation between the two session's values. A p value of 0.05 or less was accepted as statistically significant.

\section{ANALYSIS}

Data analysis was performed on a personal computer using the Statistical Package for Social Science (SPSS, Version 15). The data was collected on a master sheet designed for that purpose.

Independent sample T-test was used to compare the measurements of cerebral structures between controls and schizophrenics. The estimation result of the same observer between two sessions, the Wilcoxon Signed Rank Test was applied.

Table 1. Comparison of the mean age and body mass index (BMI) between controls and schizophrenics.

\begin{tabular}{llcc}
\hline & & The mean of age $($ Years $)( \pm$ SD $)$ & The mean of BMI $\left(\mathrm{kg} / \mathrm{m}^{2}\right)( \pm$ SD $)$ \\
\hline \multirow{2}{*}{ Male } & Control & $28( \pm$ SD 5.97) & $24( \pm$ SD 4.02)* \\
& Schizophrenic & $30( \pm$ SD 5.97) & $22( \pm$ SD 3.49)* \\
\hline \multirow{2}{*}{ Female } & Control & $29( \pm$ SD 6.14) & $25( \pm$ SD 4.83) \\
& Schizophrenic & $31( \pm$ SD 6.77) & $24( \pm$ SD 6.31) \\
\multirow{2}{*}{ Total } & Control & $29( \pm$ SD 6.01) & $25( \pm$ SD 3.38)* \\
& Schizophrenic & $31( \pm$ SD 6.31) & $23( \pm$ SD 5.08)* \\
\hline
\end{tabular}

$*_{\mathrm{p}}<0.05$ 


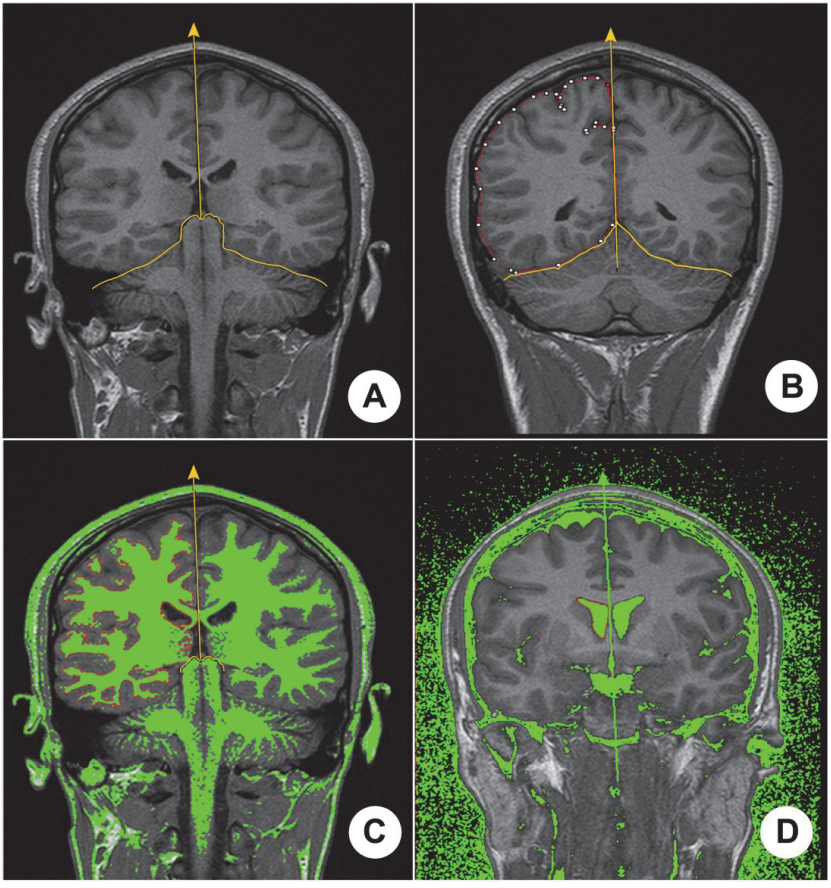

Fig. 1. Estimation of the hemispheres, white matter and ventricular size of the brains using the imageJ. A. Splitting the brain into two hemispheres in the midline and separating the cerebellum and brainstem from the hemispheres, B. Delineation the boundaries of the hemispheres, $C$. Threshold image for the measurement of white matter area, D. Threshold image for the measurement of lateral ventricle area.

\section{RESULTS}

\section{Evaluation of the volume and volume fraction of the hemispheres}

The volumes of right, left hemispheres and total volume of hemispheres showed differences between males and females within the groups and across the groups. The volumes of males were higher than the volumes of females. The volumes of schizophrenic patients were less than that of the controls. (Table 2)
The volume and the volume fraction of the right hemisphere were slightly larger than the left hemisphere. However, it did not reach to a statistically significant level. This means that the hemispheres were symmetrical both for the schizophrenic patients and controls (Table 2).

\section{Evaluation of the volume and volume fraction of the white matter}

The volumes of right, left hemispheric white matters and total volume of white matter were larger in controls than the schizophrenic patients both for males and females. In controls, there were no differences for the volumes of white matters between males and females. However, the volumes of white matter in males were less than females in schizophrenic patients (Table 3).

The volume fraction of white matter in schizophrenic patients was less for the right, left and total hemispheres indicating that the disease resulted in decrease of white matter. While the volume fractions of white matter of males were slightly lower in controls, but it did not reach to a statistically significant level. The volume fraction of white matter of males was extremely lower than the females in schizophrenic patients indicating that the volume fractional changes were severe in males compared to females in schizophrenics (Table 3).

\section{Evaluation of the volume and volume fraction of the grey matter}

The volumes of right, left hemispheric grey matter and total volume of grey matter did not differ between controls and schizophrenic patients. The volumes of right, left and total grey matters of males were higher in controls and schizophrenic patients. The volumes of grey matter of schizophrenic patients in males were higher than the controls. However, it did not reach to a statistical significant level (Table 4).

Table 2. Comparison of the mean volume and volume fraction of the cerebral hemisphere between controls and schizophrenics.

\begin{tabular}{llccccc}
\hline & & \multicolumn{2}{c}{$\begin{array}{c}\text { Volume }\left(\mathrm{cm}^{3}\right)-\mathrm{CV}(\%) \text { of } \\
\text { hemisphere }\end{array}$} & \multicolumn{2}{c}{$\begin{array}{c}\text { Volume fraction (\%) - CV (\%) of } \\
\text { hemisphere }\end{array}$} \\
\cline { 3 - 7 } & & Right & Left & Total & Right & Left \\
\hline \multirow{2}{*}{ Male } & Control & $569^{*}(7.90)$ & $568^{*}(7.78)$ & $1140^{*}(7.78)$ & $50.1(0.92)$ & $49.9(0.92)$ \\
& Schizophrenic & $543^{*}(7.94)$ & $541^{*}(8.65)$ & $1085^{*}(8.19)$ & $50.1(1.32)$ & $49.9(1.32)$ \\
\hline \multirow{2}{*}{ Female } & Control & $524^{*}(7.69)$ & $525^{*}(7.45)$ & $1050^{*}(7.54)$ & $50.0(0.72)$ & $50.0(0.72)$ \\
& Schizophrenic & $480^{*}(8.01)$ & $480^{*}(8.10)$ & $961^{*}(8.03)$ & $50.0(0.56)$ & $50.0(0.56)$ \\
\multirow{2}{*}{ Total } & Control & $551^{*}(8.8)$ & $550^{*}(8.6)$ & $1101^{*}(8.6)$ & $50.0(0.8)$ & $50.0(0.8)$ \\
& Schizophrenic & $513^{*}(10.0)$ & $512^{*}(10.3)$ & $1026^{*}(10.1)$ & $50.1(1.0)$ & $49.9(1.0)$ \\
\hline
\end{tabular}

$* \mathrm{p}<0.05$ 
Table 3. Comparison of the mean of the volume and volume fraction of the white matter between controls and schizophrenics.

\begin{tabular}{llcccccc}
\hline & \multicolumn{3}{c}{ Volume $\left(\mathrm{cm}^{3}\right)-\mathrm{CV}(\%)$ of } & \multicolumn{3}{c}{ Volume fraction (\%) - CV (\%) of } \\
& & \multicolumn{2}{c}{ white matter } & & \multicolumn{2}{c}{ white matter } \\
\cline { 3 - 8 } & & Right & Left & Total & Right & Left & Total \\
\hline \multirow{2}{*}{ Male } & Control & $271^{*}(18.2)$ & $253^{*}(18.2)$ & $525^{*}(18.1)$ & $47.7^{*}(17.0)$ & $44.7^{*}(17.6)$ & $46.2^{*}(17.2)$ \\
& Schizophrenic & $230^{*}(16.4)$ & $215^{*}(16.1)$ & $445^{*}(16.1)$ & $42.4^{*}(15.6)$ & $39.8^{*}(14.7)$ & $41.1^{*}(15.0)$ \\
\hline \multirow{2}{*}{ Female } & Control & $257^{*}(16.5)$ & $243^{*}(16.3)$ & $500^{*}(16.3)$ & $49.1(15.3)$ & $46.3(15.3)$ & $47.7(15.2)$ \\
& Schizophrenic & $236^{*}(15.8)$ & $223^{*}(15.8)$ & $459^{*}(15.4)$ & $49.1(13.2)$ & $46.5(13.8)$ & $47.8(13.3)$ \\
\hline \multirow{2}{*}{ Total } & Control & $265^{*}(17.6)$ & $249^{*}(17.5)$ & $515^{*}(17.4)$ & $48.3^{*}(16.3)$ & $45.4^{*}(16.6)$ & $46.8^{*}(16.3)$ \\
& Schizophrenic & $233^{*}(16.0)$ & $219^{*}(15.7)$ & $451^{*}(15.7)$ & $45.6^{*}(16.1)$ & $43.0^{*}(16.2)$ & $44.3^{*}(15.9)$ \\
\hline \multirow{2}{*}{$\mathrm{p}<0.05$} & & & & & &
\end{tabular}

Table 4. Comparison of the mean of the volume and volume fraction of the grey matter between controls and schizophrenics.

\begin{tabular}{|c|c|c|c|c|c|c|c|}
\hline & & \multicolumn{3}{|c|}{$\begin{array}{c}\text { Volume }\left(\mathrm{cm}^{3}\right)-\mathrm{CV}(\%) \text { of } \\
\text { grey matter }\end{array}$} & \multicolumn{3}{|c|}{$\begin{array}{l}\text { Volume fraction }(\%)-\mathrm{CV}(\%) \text { of } \\
\text { grey matter }\end{array}$} \\
\hline & & Right & Left & Total & Right & Left & Total \\
\hline \multirow{2}{*}{ Male } & & $299(18.3)$ & $315(17.5)$ & 613 (17.7) & $52.3 *(15.5)$ & $55.3 *(14.2)$ & $53.9 *(14.8)$ \\
\hline & Schizophrenic & $313(14.9)$ & $326(13.7)$ & $640(14.1)$ & $57.6^{*}(11.5)$ & $60.2 *(9.7)$ & $58.9 *(10.4)$ \\
\hline \multirow{2}{*}{ Female } & Control & $267 *(17.1)$ & $282 *(15.7)$ & $549 *(16.3)$ & $50.9(14.7)$ & $53.7(13.2)$ & $52.3(13.8)$ \\
\hline & Schizophrenic & $245^{*}(15.1)$ & $257 *(15.2)$ & $502 *(14.9)$ & $50.9(12.7)$ & $53.5(12.0)$ & $52.2(12.1)$ \\
\hline \multirow{2}{*}{ Total } & Control & $285(18.6)$ & $301(17.6)$ & $586(18.0)$ & $51.7 *(15.2)$ & $54.6^{*}(13.8)$ & $53.2 *(14.4)$ \\
\hline & Schizophrenic & $281(19.4)$ & 294 (18.6) & $574(18.8)$ & $54.4 *(13.4)$ & $57.0 *(12.2)$ & $55.7 *(12.6)$ \\
\hline
\end{tabular}

The volume fraction of grey matter in schizophrenic patients was higher for the right, left and total hemispheres indicating that the disease resulted in increase of grey matter. While the volume fractions of grey matters of females were slightly lower in controls, it did not reach to a statistically significant level. The volume fraction of grey matter of females did not show difference between the controls and schizophrenic patients (Table 4).

\section{Evaluation of the volume and volume fraction of the lateral ventricles}

The volumes of right, left lateral ventricles and total volume of lateral ventricles were higher in schizophrenic patients than controls. However, it did not reach to a statistically significant level. The volumes of right, left and total volume of lateral ventricles did not differ between males and females in controls. The volumes of the left and total lateral ventricles were higher in males than females in schizophrenic patients (Table 5).

The volume fraction of lateral ventricles in schizophrenic patients was higher for the right, left and total hemispheres indicating that the disease resulted in increase of lateral ventricles. The volume fraction of left, right and total lateral ventricles did not show difference between males and females in both controls and schizophrenic patients (Table 5).

\section{Coefficient of error (CE) estimation results for the volume data}

The CE of volume was estimated. The details of the $\mathrm{CE}$ values are given in (Table 6).

\section{Evaluation of the intra-rater variation for the estimation of volume of cerebral structures}

The mean total brain volumes of 30 subjects were $1090 \mathrm{~cm}^{3}$ and $1087 \mathrm{~cm}^{3}$ for the first and second sessions, respectively. The mean total white matter volumes were $537 \mathrm{~cm}^{3}$ for the first and second sessions, respectively. They were $554 \mathrm{~cm}^{3}$ and $549 \mathrm{~cm}^{3}$ for the total gray matter volumes in two sessions, respectively. The values for the total ventricular volumes were the same for both sessions, $14.3 \mathrm{~cm}^{3}$. Statistical analysis of the data obtained in the first and second sessions did not differ from each other $(p>0.05)$.

The correlation analysis of the estimates showed that there were high correlations between the first and second sessions. The correlation coefficient (r) for the total brain, total white matter, total grey matter and total ventricles were 0.99 . 
Table 5. Comparison of the mean of the volume and volume fraction of the lateral ventricles between controls and schizophrenics.

\begin{tabular}{|c|c|c|c|c|c|c|c|}
\hline & & \multicolumn{3}{|c|}{$\begin{array}{c}\text { Volume }\left(\mathrm{cm}^{3}\right)-\mathrm{CV}(\%) \text { of } \\
\text { lateral ventricles }\end{array}$} & \multicolumn{3}{|c|}{$\begin{array}{c}\text { Volume fraction }(\%) \text { - CV (\%) of } \\
\text { lateral ventricles }\end{array}$} \\
\hline & & Right & Left & Total & Right & Left & Total \\
\hline \multirow{2}{*}{ Male } & & $6.96(48.6)$ & $7.6^{*}(50.8)$ & $14.6(47.7)$ & $1.22(47.5)$ & $1.33 *(47.4)$ & $1.28 *(45.3)$ \\
\hline & Schizophrenic & $7.70(35.5)$ & $9.22 *(34.2)$ & $16.9(32$ & $1.42(35.9)$ & $1.70 *(31.8)$ & $1.56 *(31.4)$ \\
\hline \multirow{2}{*}{ Female } & Control & $6.13(33.9)$ & $7.06(44.2)$ & $13.2(36$ & $1.17(32.5)$ & $1.33 *(38.3)$ & $1.25 *(32.8)$ \\
\hline & Schizophrenic & $6.68(30.1)$ & $7.51(28.9)$ & $14.2(28.5)$ & $1.39(27.3)$ & $1.56 *(25.6)$ & $1.47 *(25.9)$ \\
\hline \multirow{2}{*}{ Total } & Control & $6.61(44.2)$ & $7.39(48.3)$ & $14.0(44.1)$ & $1.20 *(42.5)$ & $1.33 *(43.6)$ & $1.26 *(40.5)$ \\
\hline & Schizophrenic & $7.22(33.9)$ & $8.41(33.5)$ & $15.6(31.8)$ & $1.41 *(31.9)$ & $1.63 *(29.4)$ & $1.52 *(28.9)$ \\
\hline
\end{tabular}

Table 6. The mean coefficient of error (\%) values of the volume estimations.

\begin{tabular}{llcccccc}
\hline & $\begin{array}{c}\text { Right } \\
\text { hemisphere }\end{array}$ & $\begin{array}{c}\text { Left } \\
\text { hemisphere }\end{array}$ & $\begin{array}{c}\text { Left } \\
\text { white matter }\end{array}$ & $\begin{array}{c}\text { Right } \\
\text { white matter }\end{array}$ & $\begin{array}{c}\text { Right } \\
\text { ventricle }\end{array}$ & $\begin{array}{c}\text { Left } \\
\text { ventricle }\end{array}$ \\
\hline \multirow{2}{*}{ Male } & Control & 0.07 & 0.17 & 0.33 & 0.33 & 0.58 & 0.51 \\
& Schizophrenic & 0.18 & 0.18 & 0.31 & 0.33 & 0.50 & 0.41 \\
\hline \multirow{2}{*}{ Female } & Control & 0.17 & 0.17 & 0.32 & 0.33 & 0.65 & 0.50 \\
& Schizophrenic & 0.17 & 0.17 & 0.32 & 0.33 & 0.54 & 0.47 \\
\hline
\end{tabular}

Bland and Altman analysis (Chap 2003) was also applied to see the agreement between to session. There was a good agreement between the sessions.

\section{DISCUSSION}

The main findings of this study are that the schizophrenic patients had a reduced total cerebral $(7.33 \%)$, white matter $(14 \%)$, and grey matter $(2.12 \%)$ volumes and enlarged lateral ventricular volumes (11.7\%). Alterations of the left hemisphere in schizophrenia are found more consistently than that of the right.

The current study supports the finding of Shenton et al. (2001), The current study supports the finding of Shenton (2001), who reported the left hemisphere to be less dense than the right in twins with schizophrenia, who reported the left hemisphere to be less dense than the right in a twin with schizophrenia, while the reverse was true for their healthy co-twin and control subjects. These results imply that left hemisphere abnormality is environmentally acquired, rather than a genetic trait. The right hemisphere, especially the temporal area, develops earlier than the left for a short period of time (Geschwind and Galaburda, 1985). Therefore, if there were an insult to the fetal brain in the process of neurodevelopment, the left hemisphere would be more prone to disruption, which could be related to the pathogenesis of schizophrenia.
Although some researchers did not detect any significant difference between the cerebral hemispheric volumes of the schizophrenic patients and the healthy individuals, some others believe that in schizophrenia the cerebrum is smaller than normal. The present findings of reductions converge mostly with Olabi et al. (2011), they found that patients with schizophrenia showed significantly greater decreases over time than controls in whole-brain volume, whole-brain gray matter, frontal gray and white matter, parietal white matter, and temporal white matter volume, as well as larger increases in lateral ventricular volume.

However, there has been considerable variability in results of schizophrenia MRI studies. A number of factors may contribute to this variability, including differences in analysis methods, variability in the disorder itself, and also due to variations in sampling selection and recruitment biases concerning both patient and control samples.

On the other hand, findings of an informative quantitative postmortem schizophrenia studies support a tendency towards a slightly reduced cortical volume, without any major global deficits in cortical cell number. The field is moving toward more targeted studies of specific cell types in specific cortical areas, including laminar analyses. Although such studies have detected schizophrenia-related cortical changes, more studies are needed before a consensus can be reached (Dorph-Petersen and Lewis, 2011). 
White matter reductions were bilateral and widespread in this study. Some studies concentrate on grey matter findings, 7 studies included in the meta-analysis by Honea et al. (2005), had looked into only grey matter, whereas 7 studies had explored both tissues, and only one was restricted to white matter. Hence, the literature supporting white matter loss is not yet as strong that documenting grey matter deficit (Wright et al., 2000). However, the findings of present study imply that there are significant deficits in regional white matter tissue in schizophrenia, which can be interpreted as a loss of organization of the fibers and alteration of the myelin, and thus, white matter should not be overlooked in future morphometric studies.

The regional grey matter reductions observed in females are broadly consistent with those reported in previous structural MRI studies. In keeping with the existing literature it has been shown in this study that patients with schizophrenia have significantly lower total and regional grey matter volume when compared to age and sex matched healthy volunteers (Kasai et al., 2002). Some studies, however, have failed to reproduce these relationships (Paillere-Martinot et al., 2001). The findings of male schizophrenics in this study were quite different than those reported in the literature.

When considering differences between the study's findings, it is important to note that there are different measures calculated in different ways, and need not necessarily yield identical results. Thus, a straightforward interpretation of such differences is that they reflect regional heterogeneity in underlying pathological mechanisms. This view is consistent with ongoing debate over the cause of MRI-based grey matter reductions (Weinberger and McClure, 2002; Mathalon et al. 2003), and evidence that such reductions may not necessarily result from a unitary process (Fornito et al., 2009). For example, reductions in neuron density have commonly been found in post-mortem studies of medial temporal, medial prefrontal and thalamic regions in schizophrenic patients (Todtenkopf et al., 2005), whereas increased neuronal density, accompanied by reduced synaptic density, has been a replicated finding in lateral prefrontal areas (Glantz and Lewis, 2001).

Other authors (Sowell et al., 2003; Paus, 2005) have drawn attention to the substantial contributions made by non-neuronal tissue to grey matter estimates in T1- weighted imaging, implying that up to $1 / 3$ of the signal may originate from intracortical white matter (Braitenberg, 2001). These findings imply that grey matter reductions observed with MRI, can arise from changes to several different tissue compartments, including neurons, glia, and their processes. Better under- standing of how different histopathological changes affect MRI based grey matter changes is necessary to constrain future interpretation of neuroimaging findings. Therefore, in this study, the grey matter decreases found on MRI could be explained by either cell death and/or atrophy in females.

In schizophrenia patients, lateral ventricle enlargement is associated with smaller cortical and subcortical grey matter volumes (Weinberger and McClure, 2002). White matter reduction in proximity of the lateral ventricles can also be considered as an index of lateral ventricle enlargement (Price et al., 2006). In vivo imaging studies and post-mortem investigations have led to the conclusion that the most important morphological abnormality in schizophrenia brains is ventricular enlargement relative to ventricular size in healthy controls. Although larger lateral ventricles are the most common finding in the schizophrenia, it is not specific and can be found in a number of other disorders such as Alzheimer's disease, hydrocephalus, and Huntington's chorea. In general, enlarged lateral ventricles are interesting findings which can indicate paraventricular neuronal tissue loss or embryonic dysgenesis (Shenton et al., 2001).

The present results imply that there could be a neuroanatomical basis in the lateral ventricle volume differences between patients with schizophrenia and normal subjects; the lateralized ventricular differences that concern the left hemisphere, as numerous studies have implied that large ventricles in schizophrenia simply reflect diffuse brain atrophy. Rather, focal shrinkage in distinct gray matter regions involved in the pathophysiology of the disorder and adjacent to the ventricles might be a main contributor to this effect. This could also explain the variability in localization and extent of ventricular changes in schizophrenia. (Gaser et al., 2004)

In the present study, the patients using typical and atypical antipsychotic medication there was a relative decrease in the volumes of the two hemispheres and grey matter in addition to decrease in the volume fraction of the white matter over the interval compared with controls. At the same time we do not find evidence for ventricular volume changes.

Our findings imply that antipsychotic treatment may contribute to brain tissue volume loss. More recent literature reviews have highlighted the potential role of antipsychotics in influencing brain volume deficits in schizophrenia and its implications (Navari and Dazzan, 2009).

The present findings of reductions meet mostly with the findings of Ho et al. (2011), which noticed 
although antipsychotics relieve psychosis and its attendant suffering, these drugs may not arrest the pathophysiologic processes underlying schizophrenia and may even aggravate progressive brain tissue volume reductions.

\section{CONCLUSION}

Male schizophrenic patients had a higher grey matter volume than the controls. The volume fraction of grey matter in male schizophrenic patients was highest among the four groups in the study. While the grey matter volume fraction is symmetrical for controls and schizophrenic females, it was asymmetrical for the male schizophrenics. The left grey matter volume fraction was higher than the right one. Finally, in male patients, the lateral ventricles were asymmetrical and the volume fraction of left one was higher than the right lateral ventricles.

\section{ACKNOWLEDGEMENTS}

The authors are highly indebted to the technicians of the department of radiology in the National Ribat University/ Sudan, for their great contribution to this study and to the subjects who participated in collection of data.

This study was supported by the Organization for Women in Science for the Developing World (OWSDW)/ Italy and the Ministry of Higher Education/ Sudan. The topic of this paper was presented at the S4G Conference, June 25-28, 2012 in Prague, Czech Republic.

\section{REFERENCES}

Braitenberg V (2001). Brain size and number of neurons: an exercise in synthetic neuroanatomy. J Comput Neurosci 10:71-7.

Chap TE (2003). Comparison of population means. Introductory biostatistics (1). John Wiley and Sons. Canada, 246-81.

Doherty CP, Fitzsimons M, Holohan T, Mohamed HB, Farrell M, Meredith GE (2000). Accuracy and validity of stereology as a quantitative method for assessment of human temporal lobe volumes acquired by magnetic resonance imaging. Magn Reson Imaging 18:1017-25.

Dorph-Petersen KA, Lewis DA (2011). Stereological approaches to identifying neuropathology in psychosis. Biol Psychiatry 69:113-26.

Ebdrup BH, Skimminge A, Rasmussen H, Aggernaes B, Oranje B, Lublin H (2011). Progressive striatal and hippocampal volume loss in initially antipsychotic-naive, first-episode schizophrenia patients treated with quetiapine: relationship to dose and symptoms. Int J Neuro- psychopharmacol 14:69-82.

Elfaki A; Osman T; Elsheikh A, Hamdoun A; Sahin B (2011). Evaluation of the intra-rater variation for the estimation of volume of cerebral structures using the cavalieri principle on magnetic resonance images. J Exp Clin Med 28:22-5.

Fornito A, Yucel M, Dean B, Wood SJ, Pantelis C (2009). Anatomical abnormalities of the anterior cingulate cortex in schizophrenia: bridging the gap between neuroimaging and neuropathology. Schizophr Bull 35:973-93.

Garcia-Finana M, Cruz-Orive LM, Mackay CE, Pakkenberg B, Roberts N (2003). Comparison of MR imaging against physical sectioning to estimate the volume of human cerebral compartments. Neuroimage 18:505-6.

Gaser C, Nenadic I, Buchsbaum BR, Hazlett EA, Buchsbaum MS (2004). Ventricular enlargement in schizophrenia related to volume reduction of the thalamus, striatum, and superior temporal cortex. Am J Psychiatry 61:154-6.

Geschwind N, Galaburda AM (1985). Cerebral lateralization. Biological mechanisms, associations, and pathology: I. A hypothesis and a program for research. Arch Neurol 42:428-59.

Glantz LA, Lewis DA (2001). Dendritic spine density in schizophrenia and depression. Arch Gen Psychiatry 58: 203.

Gong QY, Roberts N, Garden AS, Whitehouse GH (1998). Fetal and fetal brain volume estimation in the third trimester of human pregnancy using gradient echo MR imaging. Magn Reson Imaging 16:235-40.

Gundersen HJ, Jensen EB, Kiêu K, Nielsen J (1999). The efficiency of systematic sampling in stereology - reconsidered. J Microsc 193:199-211.

Ho BC, Andreasen NC, Ziebell S, Pierson R, Magnotta V (2011). Long-term antipsychotic treatment and brain volumes: A longitudinal study of first-episode schizophrenia. Arch Gen Psychiatry 68:128-37.

Honea R, Crow TJ, Passingham D, Mackay CE (2005). Regional deficits in brain volume in schizophrenia: a meta-analysis of voxel-based morphometry studies. Am J Psychiatry 162:2233-45.

Kasai K, Iwanami A, Yamasue H, Kuroki N, Nakagome K, Fukuda M (2002). Neuroanatomy and neurophysiology in schizophrenia. Neurosci Res 43:93-110.

Kubicki M, McCarley RW, Shenton ME (2005). Evidence for white matter abnormalities in schizophrenia. Curr Opin Psychiatry 18:121-34.

Kubicki M, McCarley R, Westin CF, Park HJ, Maier S, Kikinis R (2007). A review of diffusion tensor imaging studies in schizophrenia. J Psychiatr Res 41:15-30.

Mathalon DH, Rapoport JL, Davis KL, Krystal JH (2003). Neurotoxicity, neuroplasticity, and magnetic resonance imaging morphometry. Arch Gen Psychiatry 60:848-9.

Mazonakis M, Damilakis J, Maris T, Prassopoulos P, Gourtsoyiannis N (2002). Comparison of two volumetric techniques for estimating liver volume using magnetic resonance imaging. J Magn Reson Imaging 15: 557-63. 
Navari S, Dazzan P (2009). Do antipsychotic drugs affect brain structure? a systematic and critical review of MRI findings. Psychol Med 39:1763-77.

Olabi B, Ellison-Wright I, McIntosh AM, Wood SJ, Bullmore E, Lawrie SM (2011). Are there progressive brain changes in schizophrenia? A meta-analysis of structural magnetic resonance imaging studies. Biol Psychiatry 70: 88-96.

Paillere-Martinot M, Caclin A, Artiges E, Poline JB, Joliot M, Mallet L (2001). Cerebral gray and white matter reductions and clinical correlates in patients with early onset schizophrenia. Schizophr Res 50:19-26.

Paus T (2005). Mapping brain maturation and cognitive development during adolescence. Trends Cogn Sci 9:60-8.

Peralta V, Cuesta MJ (2011). Eugen Bleuler and the schizophrenias: 100 years after Schizophr Bull 37:1118-20.

Price G, Cercignani M, Bagary MS, Barnes TR, Barker GJ, Joyce EM (2006). A volumetric MRI and magnetization transfer imaging follow-up study of patients with firstepisode schizophrenia. Schizophr Res 87:100-8.

Rajarethinam RP, DeQuardo JR, Nalepa R, Tandon R (2000). Superior temporal gyrus in schizophrenia: a volumetric magnetic resonance imaging study. Schizophr Res 41:303-12.

Sanfilipo M, Lafargue T, Arena L, Rusinek H, Kushner K, Lautin A (2000). Fine volumetric analysis of the cerebral ventricular system in schizophrenia: further evidence for multifocal mild to moderate enlargement. Schizophr Bull 26:201-16.

Shenton ME, Dickey CC, Frumin M, McCarley RW (2001). A review of MRI findings in schizophrenia. Schizophr Res 49:1-52.

Smith RC, Calderon M, Ravichandran GK, Largen J, Vroulis G, Shvartsburd A (1984). Nuclear magnetic reso-nance in schizophrenia: a preliminary study. Psychiatry Res 12: 137-47.
Sowell ER, Levitt J, Thompson PM, Holmes CJ, Blanton RE, Kornsand DS (2000). Brain abnormalities in earlyonset schizophrenia spectrum disorder observed with statistical parametric mapping of structural magnetic resonance images. Am J Psychiatry 157:1475-84.

Sowell ER, Peterson BS, Thompson PM, Welcome SE, Henkenius AL (2003). Mapping cortical change across the human life span. Nat Neurosci 6:309-15.

Spitz H, Sadock BJ (1973). Small interactional groups in the psychiatric training of graduate nursing students. J Nurs Educ 12:6-13.

Thompson PM, Vidal C, Giedd JN, Gochman P, Blumenthal J, Nicolson R (2001). Mapping adolescent brain change reveals dynamic wave of accelerated gray matter loss in very early-onset schizophrenia. Proc Natl Acad Sci USA 98:11650-5.

Todtenkopf MS, Vincent SL, Benes FM (2005). A crossstudy meta-analysis and three-dimensional comparison of cell counting in the anterior cingulate cortex of schizophrenic and bipolar brain. Schizophr Res 73:79-89.

Vidal CN, Rapoport JL, Hayashi KM, Geaga JA, Sui Y, McLemore LE (2006). Dynamically spreading frontal and cingulate deficits mapped in adolescents with schizophrenia. Arch Gen Psychiatry 63:25-34.

Walterfang M, Wood SJ, Velakoulis D, Pantelis C (2006). Neuropathological, neurogenetic and neuroimaging evidence for white matter pathology in schizophrenia. Neurosci Biobehav Rev 30:918-48.

Weinberger DR, McClure RK (2002). Neurotoxicity, neuroplasticity, and magnetic resonance imaging morphometry: what is happening in the schizophrenic brain? Arch Gen Psychiatry 59:553-8.

Wright IC, Rabe-Hesketh S, Woodruff PW, David AS, Murray RM, Bullmore ET (2000). Meta-analysis of regional brain volumes in schizophrenia. Am J Psychiatry 157:16-25. 